BBA 35934

\title{
CYANATE FORMATION IN SOLUTIONS OF UREA
}

\section{EFFECT OF UREA ON THE EYE LENS PROTEIN $\alpha$-CRYSTALLIN}

\author{
J. J. T. GERDING, A. KOPPERS, P. HAGEL* AND H. BLOEMENDAL** \\ Department of Biochemistry, University of Nijmegen, Nijmegen (The Netherlands)
}

(Received April 8th, I97I)

\section{SUMMARY}

It has been demonstrated by comparative electrophoresis on polyacryalmide gels, that long contact of $\alpha$-crystallin with urea eventually gives rise to a high degree of carbamylation. This may lead to erroneous conclusions about the number of real subunits, especially as the preparation of these subunits has to be carried out in high urea concentrations.

Purification of urea on a mixed bed resin is of limited meaning as new cyanate formation occurs at $\mathrm{pH}$ higher than 4 .

It has also been shown, that co-electrophoresis by means of the split gel technique gives misleading results when freshly prepared samples are compared with samples kept in urea for a longer period of time.

INTRODUCTION

In the preceeding paper ${ }^{1}$ we have presented a calculation of cyanate concentrations in aqueous solutions of urea. It appeared, that the accumulation of cyanate ions is most pronounced at a $\mathrm{pH}$ higher than 4 . As a practical application we have studied the effect of cyanate on solutions of the lens protein $\alpha$-crystallin in urea by acrylamide gel electrophoresis at a fixed $\mathrm{pH}$ of 8.9 in $6 \mathrm{M}$ urea under varying conditions.

\section{MATERIALS AND METHODS}

Potassium cyanate was obtained from B.D.H. and urea (pro analysis grade) from Merck, Darmstadt.

Bovine $\alpha$-crystallin was prepared according to ScHoENMAKERs et al. ${ }^{2} .6 \mathrm{M}$ urea solutions were prepared by dissolving urea in cold water, in some experiments followed lands.

* Present address: National Institute for Fisheries Investigation, IJ muiden, The Nether-

** To whom requests for reprints should be addressed.

Biochim. Biophys. Acta, 243 (1971) 374-379 


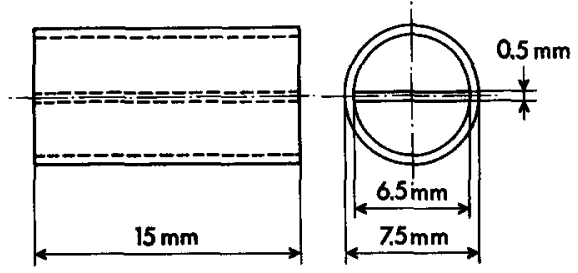

Fig. I. Adaptor for the gel tube in the split gel technique.

by purification on a mixed bed ion exchange column. As this step appeared to be of little influence on the electrophoretic patterns it was omitted. Polyacrylamide gel electrophoresis was performed according to BLOEMENDAL ${ }^{3}$ in $6 \mathrm{M}$ urea at $5 \mathrm{~mA}$ per gel tube for I h. The gels were stained with Amido Black. Excess stain was removed electrophoretically. The split gel procedure was carried out as follows.

All chemicals were the same as for the normal technique. However, the dimension of the gel tubes differed $(8 \mathrm{~cm} \times 7.5 \mathrm{~mm})$. In order to allow careful separate insertion of the samples, a thin plastic adaptor was made and applied on top of the tube (Fig. I). Electrophoresis was carried out at $7.5 \mathrm{~mA}$ for $90 \mathrm{~min}$.

\section{RESULTS AND DISCUSSION}

Electrophoresis was carried out with the following solutions of $\alpha$-crystallin: (I) freshly prepared; (2) after prolonged standing in $6 \mathrm{M}$ urea; (3) after prolonged

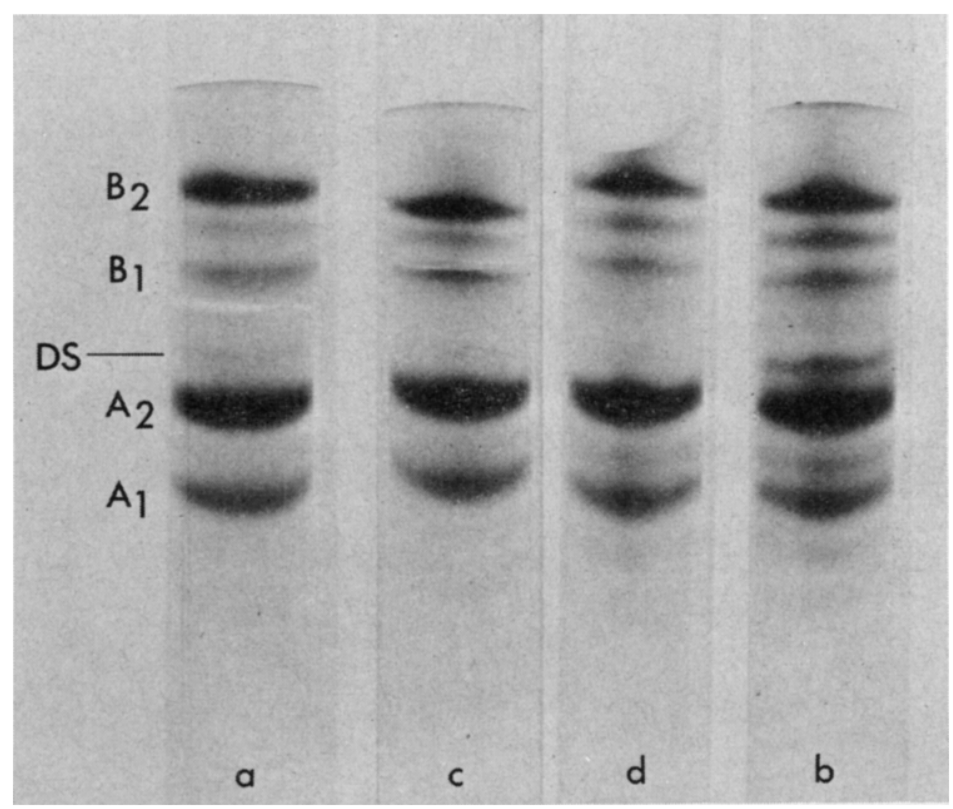

Fig. 2. Polyacrylamide gel electrophoresis of $\alpha$-crystallin in $6 \mathrm{M}$ urea. a. Sample dissolved in $6 \mathrm{M}$ urea and applied immediately to the gel column. b. Sample disoslved in $6 \mathrm{M}$ urea and applied after $24 \mathrm{~h}$. c. Sample dissolved in $6 \mathrm{M}$ urea $+\mathrm{I} \mathrm{mM}$ dithiothreitol and applied immediately to the gel column. d. Sample dissolved in $6 \mathrm{M}$ urea $+\mathrm{I} \mathrm{mM}$ dithiothreitol and applied after $24 \mathrm{~h}$. 
standing in $6 \mathrm{M}$ urea which had been enriched with cyanate ions; (4) totally carbamylated according to the method of STARK ${ }^{4}$.

Fig. 2a shows the electrophoretic pattern of freshly prepared $\alpha$-crystallin. In addition to a few very faint zones three rather strong bands and one weaker band are visible. These bands correspond to polypeptide chains $A_{1}, A_{2}, B_{1}$ and $B_{2}$ respectively. This nomenclature is according to BloEmendaL ${ }^{5}, A_{1}$ and $A_{2}$ representing the acidic and $B_{1}$ and $B_{2}$ the basic polypeptide chains of $\alpha$-crystallin. The significance of all very faint zones has not yet been elucidated. DS is a dimer of the acidic chains. Others may represent enzymes which are known to be present in very low concentrations in the eye lenses. Leucine amino peptidase is one of these enzymes ${ }^{6}$. In Fig. $2 \mathrm{~b}$ the electrophoretic pattern of $\alpha$-crystallin after $24 \mathrm{~h}$ standing in $6 \mathrm{M}$ urea at $\mathrm{pH} 8.9$ at room temperature is shown. New bands arise: one band between $A_{1}$ and $A_{2}$, one between DS and $B_{1}$ whereas a number of faint bands appear stronger. Control experiments reveal that the zone between $A_{2}$ and $B_{1}$ actually represents the dimer of the acidic chains. When I $\mathrm{mM}$ dithiothreitol is added to the sample prior to electrophoresis this zone almost disappears (compare Figs. $2 \mathrm{c}$ and $2 \mathrm{~d}$ ). Moreover, it has been reported that this zone is never present in carboxymethylated $\alpha$-crystallin ${ }^{7}$. The band between $\mathrm{B}_{2}$ and $\mathrm{B}_{1}$ always appears very rapidly after dissolving of the protein in urea by traces of cyanate ions which are present even in freshly prepared urea solutions.

The effect of $6 \mathrm{M}$ urea after 4 days standing of the protein sample at two different temperatures is shown in Fig. 3. There is only a small difference between incubation at $5^{\circ}$ and at $22^{\circ}$; some bands are slightly more intense at room temperature, but apparently there is no change in the number of bands. When cyanate is added

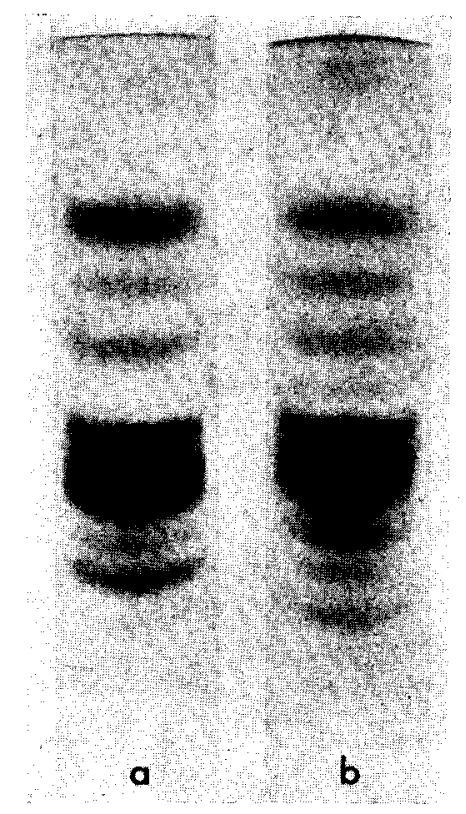

Fig. 3. Polyacrylamide gel electrophoresis of $\alpha$-crystallin in $6 \mathrm{M}$ urea. Effect of time and temperature. a. Sample stored in $6 \mathrm{M}$ urea at $5^{\circ}$ for 4 days. b. Sample stored in $6 \mathrm{M}$ urea at $20^{\circ}$ for 4 days. 


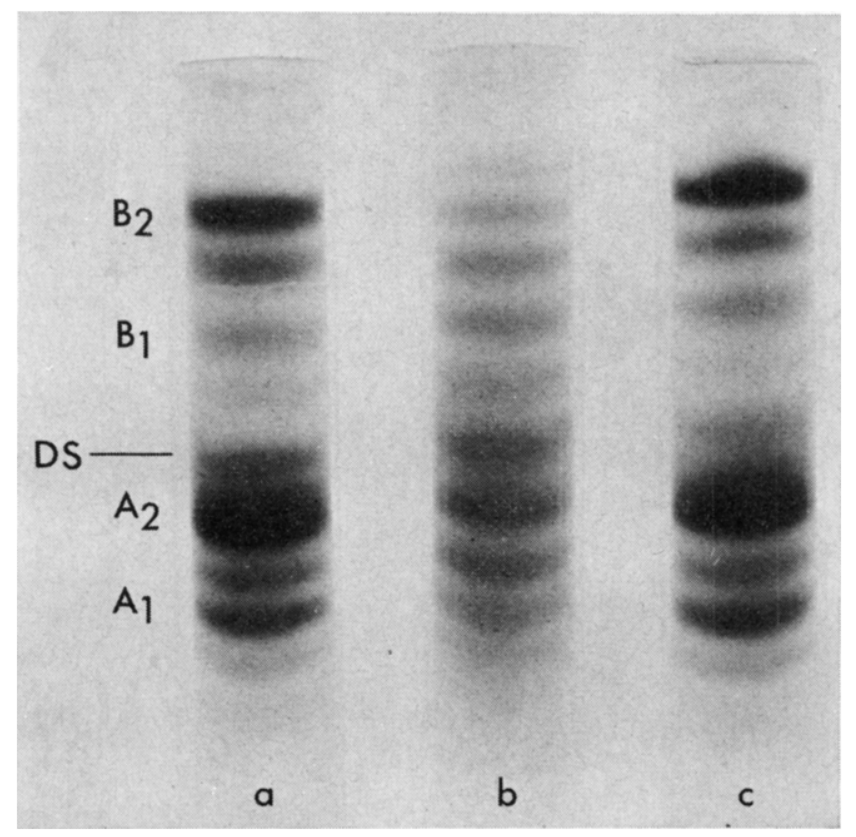

Fig. 4. Polyacrylamide gel electrophoresis of $a$-crystallin. Effect of cyanate ions. a. Sample incubated in $6 \mathrm{M}$ urea at $20^{\circ}$ for $24 \mathrm{~h}$. The urea was enriched with $0.4 \mathrm{mg} \mathrm{KNCO}$ per ml. b. Sample incubated in $6 \mathrm{M}$ urea at $20^{\circ}$ for $24 \mathrm{~h}$. The urea was enriched with $4.3 \mathrm{mg}$ KNCO per ml. c. Sample incubated in $6 \mathrm{M}$ urea at $5^{\circ}$ for $24 \mathrm{~h}$. The urca was enriched with $4.3 \mathrm{mg} \mathrm{KNCO}$ per $\mathrm{ml}$.

to the sample in $6 \mathrm{M}$ urea solution the electrophoretic pattern changes remarkably (Fig. 4). Fig. 4a visualizes the pattern at room temperature and rather low cyanate concentration. The effect is dramatic when the concentration of cyanate is raised at room temperature (Fig. 4 b). Equalization of the intensity of all zones occurs. Exposure to high cyanate concentration at $5^{\circ}$ results in the same pattern as exposure to low cyanate at higher temperature (compare Fig. 4a with $4 \mathrm{c}$ ). The results of a series of experiments with a variety of incubations, all performed at room temperature, are shown in Fig. 5 .

When the protein sample is exposed to $6 \mathrm{M}$ urea for $24 \mathrm{~h}$ before electrophoresis the pattern as shown in Fig. 5 a is obtained. Fig. 5 b gives the pattern when the incubation is extended to ten days. Some bands vanish presumably due to progressing carbamylation. In order to confirm this assumption the urea solution was enriched with cyanate ions. Fig. $5 \mathrm{c}$ visualizes the influence of low cyanate and Fig. $5 \mathrm{~d}$ of high cyanate concentration. The disappearance of bands and appearance of others is promoted by higher cyanate concentration. The pattern after total carbamylation is shown in Fig. 5e. For comparison the pattern of $\alpha$-crystallin exposed for 5 weeks to $6 \mathrm{M}$ urea is added, Fig. $5 \mathrm{f}$. Carbamylation results in increased electrophoretic mobility of the individual zones, due to the elimination of positive groups in the protein. This is clearly shown by the split gel technique (Fig. 6). A totally carbamylated sample has been run in the same gel as pure $\alpha$-crystallin dissolved in $6 \mathrm{M}$ urea. From this example it can be concluded that the split gel technique fails, when freshly prepared samples 

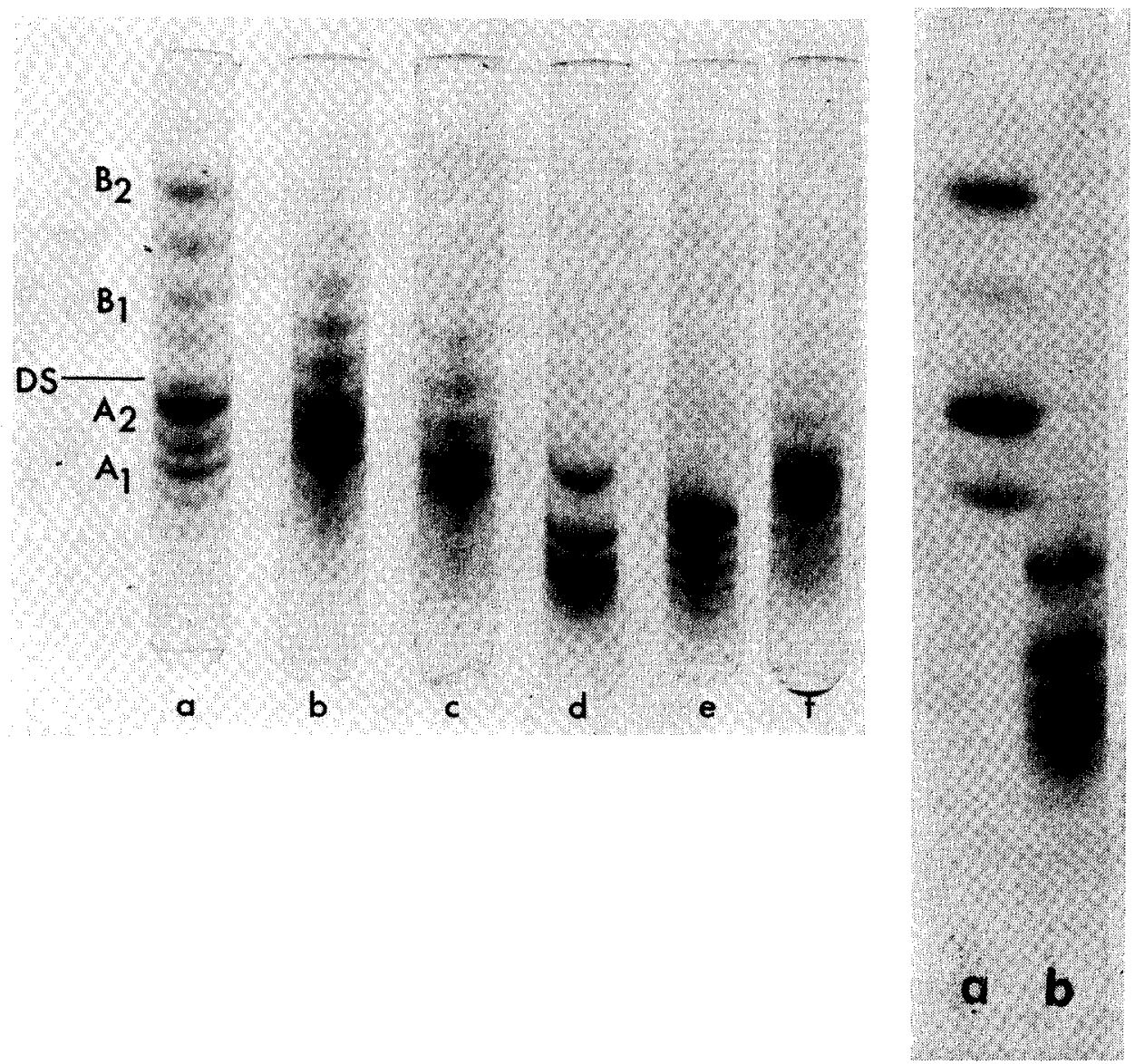

Fig. 5. Comparative polyacrylamide gel electrophoresis of urea-treated, partially and totally carbamylated $\alpha$-crystallin. a. Sample incubated in $6 \mathrm{M}$ urea for $24 \mathrm{~h}$. b. Sample incubated in $6 \mathrm{M}$ urea for Io days. c. Sample incubated in $6 \mathrm{M}$ urea enriched with $0.4 \mathrm{mg} / \mathrm{ml} \mathrm{KNCO}$ for Io days. d. Sample incubated in $6 \mathrm{M}$ urea enriched with $4.3 \mathrm{mg} / \mathrm{ml} \mathrm{KNCO}$ for Io days. e. Sample totally carbamylated. f. Sample incubated in $6 \mathrm{M}$ urea for 5 weeks.

Fig. 6. Split gel electrophoresis of $\alpha$-crystallin. a. $\boldsymbol{a}$-Crystallin dissolved in 6 M urea and applied immediately to the gel. b. $\alpha$-Crystallin totally carbamylated.

and samples which were in contact with urea for a longer space of time are compared. This is not merely a theoretical consideration. When, e.g. the polypeptide chains of $\alpha$-crystallin have to be separated this is achieved on columns containing high urea concentrations. After isolation the separated chains cannot be compared with fresh $\alpha$-crystallin dissolved in urea on base of electrophoretic mobility; at least when the fractionation took place at a $\mathrm{pH}$ higher than 4 .

Summarizing we can say, that from the results of the electrophoretic experiments the conclusion may be drawn, that the effect of long contact of $\alpha$-crystallin with concentrated urea solution is similar to the effect of incubation of the protein for a shorter time in KNCO-enriched urea solution; long contact eventually giving totally carbamylated $\alpha$-crystallin. These effects are readily understood in terms of the 
calculated formation of cyanate ions in aqueous urea solutions. It has been pointed out in the preceeding paper ${ }^{1}$, that the formation of the cyanate ions in urea solutions is extremely slow, especially at low temperatures. Therefore the enrichment of urea with cyanate will enhance the carbamylation of the protein. As cyanate accumulates in urea during long standing the same effect is observed after the enrichment of urea solutions with cyanate. This was shown by comparison of $\alpha$-crystallin standing for a very long time in urea and $\alpha$-crystallin standing for ro days in "cyanate-enriched" urea.

\section{ACKNOWLEDGEMENTS}

The present investigations have partly been carried out under auspices of the Netherlands Foundation for Chemical Research (S.O.N.) and with financial aid from the Netherlands Organization for the advancement of Pure Research (Z.W.O.).

\section{REFERENCES}

i P. Hagel, J. J. T. Gerding, W. Fieggen and H. Bloemendal, Biochim. Biophys. Acta, 243 (I97I) 266.

2 J. G. G. Schoenmakers, H. Hoenders and H. Bloemendal, Exp. Eye Res., 7 (1968) 172.

3 H. Bloemendal, Zone Electrophoresis in Blocks and Columns, Elsevier, Amsterdam, 1963, p. 65.

4 G. R. Stark and D. G. Smyth, J. Biol. Chem., 238 (1963) 2 I4.

5 H. Bloemendal, Exp. Eye Res., 8 (ig69) 227.

6 K. De Groot, H. Hoenders, A. Leon and H. Bloemendal, Exp. Eye Res., Io (1970) 7 I.

7 J. G. G. Schoenmakers and H. Bloemendal, Nature, 220 (ig68) 790.

Biochim. Biophys. Acta, 243 (1971) 374-379 